THE INTERNATIONAL

REVIEW OF RESEARCH IN

OPEN AND DISTANCE LEARNING

\title{
Using mLearning and MOOCs to Understand Chaos, Emergence, and Complexity in Education
}


Inge deWaard', Sean Abajian², Michael Sean Gallagher ${ }^{3}$, Rebecca Hogue ${ }^{4}$, Nilgün Keskin ${ }^{5}$, Apostolos Koutropoulos ${ }^{6}$, and Osvaldo C. Rodriguez ${ }^{7}$

Athabasca University, Canada', Los Angeles Unified School District, USA ${ }^{2}$, JSTOR, USA ${ }^{3}$, University of Ottawa, Canada ${ }^{4}$, Anadolu University, Turkey ${ }^{5}$, University of Massachusetts, USA ${ }^{6}$, Universidad Nacional de La Plata, Argentina ${ }^{7}$

\section{Abstract}

In this paper, we look at how the massive open online course (MOOC) format developed by connectivist researchers and enthusiasts can help analyze the complexity, emergence, and chaos at work in the field of education today. We do this through the prism of a MobiMOOC, a six-week course focusing on mLearning that ran from April to May 2011. MobiMOOC embraced the core MOOC components of self-organization, connectedness, openness, complexity, and the resulting chaos, and, as such, serves as an interesting paradigm for new educational orders that are currently emerging in the field. We discuss the nature of participation in MobiMOOC, the use of mobile technology and social media, and how these factors contributed to a chaotic learning environment with emerging phenomena. These emerging phenomena resulted in a transformative educational paradigm.

Keywords: Mobile technology; complexity; mLearning; MobiMOOC; MOOC; collaborative learning; chaos theory; emergence 


\section{Introduction}

In December 1972, Edward Lorenz presented a paper to the National Academy of Sciences in New York, titled "Predictability: Does the Flap of a Butterfly's Wings in Brazil Set off a Tornado in Texas?" This paper introduced what we now know as chaos theory. Chaos theory was only emerging at that time, but it shook the scientific world as it helped describe outcomes for complex systems that were impacted by a variety of factors. As chaos theory became more widely accepted, experts in other fields, including educational research, started to employ it to predict future frameworks.

In the reality of the 21st century's second decennium, education is molded by a variety of new factors. The use of social media, new mobile technologies, and pedagogical formats has a major impact on the learning and teaching processes of today. Due to these new technologies and emerging formats, education has been forced into a process of transformation, and that causes an imbalance at first. However, Reigeluth (2004) writes,

Chaos theory and the sciences of complexity can help us to understand our present systems of education, including (a) when each is ready for transformation, and (b) the system dynamics that are likely to influence individual changes we try to make and the effects of those changes.

Once we understand the dynamics of these new processes, we can find a new educational balance.

In these times of great complexity, we believe a pedagogical format that embeds and even embraces this complexity, combined with a prevalent emerging technology, can be the means to arrive at a new educational order. In this case, the pedagogical format is a massive open online course (MOOC) and the emerging technology is mobile learning (mLearning). We are certain combining technologies that embrace the complexity of knowledge production with pedagogical formats that allow learners to build knowledge by filtering that complexity will encourage a new educational balance to emerge. This balance will possibly enable the construction of a redesigned educational landscape that better fits this Knowledge Age. We use the word "possibly" to refer to Davis and Sumara's (2008) statement that "an education that is understood in complexity terms cannot be conceived in terms of preparation for the future. Rather, it must be construed in terms of participation in the creation of possible futures" (p. 43). It is our belief that the MOOC format allows massive participation leading to the creation of possible educational futures.

\section{Research Methodology}

The research methodology of this study is a research-based case study. The research-based design is the mobile massive open online course (MobiMOOC). For the case study research, we collected data from the final survey completed by MobiMOOC participants at the end of the six-week course. The survey posed questions on participation, level of familiarity 
with mobile technology, profession, gender, and other demographics. These data were then used to evaluate the hypothesis that MOOCs and the innovative elements of mLearning and social media can add to a new educational equilibrium based on an analysis incorporating chaos theory, emergence, and complexity theory. We were participants and researchers in the MobiMOOC.

\section{The Problem}

"The beginning of the new millennium has been described variously as an Information Age, a Digital Age, or a Knowledge Society" (Moore \& Kearsley, 2005, p. 288). No matter which label it is given, we agree with McNeely and Wolverton (2008) when they stated that "we are living through one of the recurring periods in world history when far-reaching changes in economics, culture, and technology raise basic questions about the production, preservation, and transmission of knowledge" (p. 7). This shift also has a profound effect on the leading education model used in the Industrial Age that has served as the balanced pedagogical framework for the past century. While the educational model of the Industrial Age focused on the linear transmission of information and knowledge, educators of this era search for a system dynamic enough to complement the new realities of the Knowledge Age. Chaos theoreticians argue that the nonlinear characteristics of the human mind and social interaction render the Industrial Age paradigm of teaching ineffective and deeply flawed (Cafolla, 2008). But if the education provided in the Industrial Age system is flawed, then educational researchers have to develop one or several new educational system(s) that fit this Knowledge Age and take into account the emerging technologies and learning/teaching realities of today. One such example, the MOOC, is addressed here.

There are currently two major technologies that have great influence on contemporary educational discourse, social media and mobile technologies, both of which impact learning in a profound way. Since 2005 mobile devices, social media, and the related learning that is facilitated by these new technologies have grown exponentially. The design for learning with mobile technologies is still tentative and exploratory, as mentioned by Kukulska-Hulme and Traxler (2007). However, several characteristics of mobile learning have emerged, including the importance of networks.

This rise of new educational forms (both from a pedagogical and technical point of view) has resulted in a quest for new learning methodologies and frameworks (McAuley, Stewart, Siemens, \& Cormier, 2010). "As new systems arise, so do new possibilities and new laws that cannot be anticipated, even with the most intimate knowledge of the components or agents comprising the new system" (Davis \& Sumara, 2010). If we look at the rise of social media and technology and the increased information production resulting from the read-write Web, we cannot help but turn to complexity theory for ways to develop new educational systems that incorporate this dimension. MobiMOOC brought together three innovations linked to the Knowledge Age: mobile technology, social media, and the MOOC as its learning and teaching format. We acknowledge that an investigation of a MobiMOOC will not result in a complete educational framework for this era, but it will reveal many of 
the factors that impact contemporary education. By analyzing the MobiMOOC's complexity and emerging behaviors, we hope to add valuable information to the quest for a new educational framework and equilibrium.

In the first part of this paper, we will describe the MobiMOOC. In the second part, we will analyze the MobiMOOC and its components in relation to complexity theory while looking at activities that emerge from the course.

\section{Background: The MobiMOOC}

\section{General Overview of the Course}

The MobiMOOC (see http://mobimooc.wikispaces.com/) was organized by Inge de Waard, running from 2 April to 14 May 2011, and she remained present throughout the duration of the course both as one of the facilitators and the overall coordinator. The six-week course focused on mLearning and used the MOOC format to deliver course resources and interact with all the participants. The course was free to anyone interested in the topic of mLearning, placing it within the principles of open educational resources (OER), and after completion of the course the content was made available via open source content platforms.

The MobiMOOC lasted six weeks, and each week focused on a different aspect of mLearning. Each week, a different mLearning expert facilitated the course. To ensure that participants were all on the same level, the course started with an introduction week on mLearning (facilitated by Inge de Waard), followed by mLearning planning (Judy Brown), mLearning for development (Niall Winters), leading edge innovations in mLearning (David Metcalf), interaction between mLearning and a mobile-connected society (John Traxler), and mLearning in K-12 (Andy Black). All the facilitators were guides on the side, each putting forward as many learning actions and follow-ups as they wanted because each was voluntarily engaged in the course.

\section{Some MobiMOOC Numbers}

By 14 May 2011, at the end of the course, the following activity was observed:

- 556 participants had joined the Google group over the six weeks when the course was running; however, only a limited number of them actively posted ideas or comments to the group discussions. After taking out those MobiMOOC group members who did not post anything (potential lurkers) and those who only posted a welcome message, there were 74 active (contributing) members.

- 1,827 discussion threads were started.

- There were 1,123 tweets on Twitter with the \#mobimooc hashtag (see Figure 1). This is particularly interesting as it demonstrates the highs and lows of activity for \#mobimooc tweets, as well as SMS text messages, voice calls, and Web site submissions. 
Clearly, the highest concentration of activity occurred during the weekly synchronous MobiMOOC presentations that happened on Monday. The class was given on Brussels, Belgium time (CET).

- 335 mLearning links were shared among the participants via the social bookmarking site Delicious.

- 32 participants completed the course as memorably active participants.

- 40 participants completed and submitted the final MobiMOOC survey from which we will draw conclusions.

After the course had ended there were 74 actively contributing participants (that is, individuals who wrote more than just the personal introduction comment). Forty participants completed and submitted the MobiMOOC survey (0.53\%).

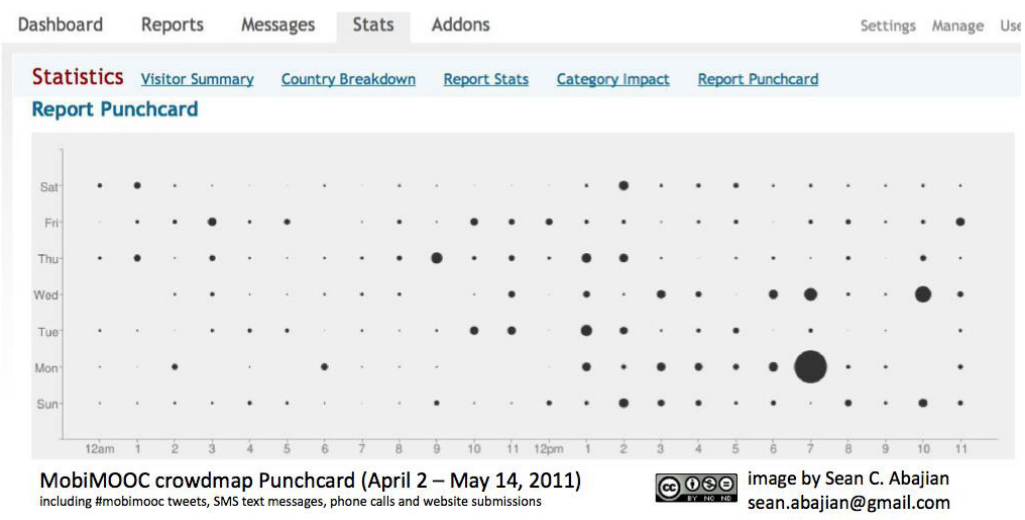

Figure 1. MobiMOOC crowdmap punch card, including \#mobimooc tweets.

Taking into account the diversity of MobiMOOC interactions, one can see it or any MOOC as a complex system. In the next part of the paper, we analyze the MobiMOOC as a complex system with its emerging phenomena and focus on dialogue forming the center of the class's meaning.

\section{The MOOC as a Complex System}

Organic pedagogical models correspond to and embrace vital conditions of self-organization, including fluid realm, openness to the information flow, turbulences and changes; freedom within flexible boundaries, richness of possibilities, interconnectedness of all parts of the system, and collective emergence. (Laroche, Nicol, \& Mayer-Smith, 2007, p. 74) 
We believe these vital conditions of self-organization-openness of information flow, freedom, interconnectedness, and collective emergence-can all be found in MOOCs. In this section of the paper, we look at a MOOC as a complex system embracing these vital conditions, using the data of the MobiMOOC as an example.

If a system is out of balance-in this case, the overall educational framework-numerous factors are influencing it in order to establish a new, sustainable equilibrium. Attaining a new balance is challenging, as chaos theory dictates that any seemingly small factor can have a major impact on the outcomes of the newly changed world. Hence the smallest change can affect, often negatively, the larger system. As such, it is important to analyze the characteristics of the MobiMOOC. By examining the characteristics of emerging educational formats, researchers can find a better direction to move in to obtain a new educational balance fitting the Knowledge Age.

\section{A MOOC is Self-Organizing}

A MOOC can be defined as a complex system that, in order to survive and develop, is continuously in search of new ways to interpret the events of the external world. As a consequence of the feedback it receives from the environment regarding its actions, the MOOC self-organizes, displaying emergent properties to interact with the environment in which it finds itself (Bertuglia, 2005). Reigeluth (2004) mentioned that systems require three characteristics: openness, self-reference, and freedom for people to make their own decisions about changes. He continued by stating that in order for a system to be open to its environment, it must actively seek information from its surroundings and make this knowledge widely available. This is exactly what happened in the MobiMOOC and what happens in MOOCs in general. The participants, by using open knowledge distribution repositories like the Web, share their experiences with others. These others can then give feedback to the MOOC, either positive or negative. This affects the learning system as it changes its structure to respond to the participants' dynamics. Such a reaction is interesting for in order for the system to adapt, it must be pushed out of balance first. This fits with what Laroche et al. (2009) wrote, "self-organization can occur in the realm of fluidity if the system is pushed out of equilibrium via some turbulence, gradients, or tension. The further the system is from equilibrium; the stronger the chance for self-organization" (p. 5).

An example of self-reference from the MobiMOOC is an interesting discussion that emerged on the issue of copyright. Some papers provided by instructors during the course were only accessible via paid library subscriptions. This resulted in a discussion about the belief that resources in a MOOC should be freely accessible to all. The freedom participants had to make their own decisions is illustrated by their ability to choose which tools they would use

to disseminate or capture their thoughts about the course. This freedom and self-reference both reveal the MOOC as a self-organizing system.

\section{A MOOC is Connected and Open}

Iannone (1995) wrote that using a chaos theory framework, today's curriculum should be 
flexible, open, disruptive, uncertain, and unpredictable, but it must also accept tension, anxiety, and problem-creating as the norm for the transformation process. The format of a MOOC is by definition open and online. In order to allow as many participants as possible to join the course, its resources are accessible via the Web. Laroche et al. (2009) added that "fluid environments have fuzzy and penetrable boundaries; they blur distinctions between schools, universities, nature and society, while juxtaposing formal and informal educational settings. Fluid environments are conducive to emerging non-orthodox forms of educational research" (p. 6). This fluidity can be placed within the connectivism theory from which MOOCs emerged. Additionally, this openness implies that a system should be willing to transform, indeed embrace the process as a natural product of openness and selforganization.

\section{Connectivism and MOOCs}

MobiMOOC was built on the concept of the massive open online course (MOOC). Two separate individuals, Bryan Alexander and Dave Cormier, first mentioned the term MOOC. The concepts behind MOOCs were first introduced by Stephen Downes and George Siemens while they were developing a course format to fit with the theory of connectivism; this course came to be known as Connectivism and Connective Knowledge (CCK). "In connectivism, the starting point for learning occurs when knowledge is actuated through the process of a learner connecting to and feeding information into a learning community" (Kop \& Hill, 2008, p. 2). Kop and Hill (2008) went further, stating, "connectivism stresses that two important skills that contribute to learning are the ability to seek out current information, and the ability to filter secondary and extraneous information" (p. 2). This connectivism embraces complexity theory when referring to the organization of the course, which enables participants to connect outside of the learning environment and influence the course simultaneously. Mackness, Mak, and Williams (2010) found that when the theory of connectivism is used in the practice of a MOOC, its network principles of diversity, autonomy, openness, and emergent knowledge are included, giving it the characteristics of a complex system.

\section{Transformation of the MOOC System}

To stay viable, open systems maintain a state of nonequilibrium ... they participate in an open exchange with their world, using what is there for their own growth ... that disequilibrium is the necessary condition for a system's growth. (Wheatley, 1999, p. 78-79)

This constant flux is an inherent part of a MOOC. Nevertheless, even in this supposed chaos we can find stability in the seemingly strange attractors that occur.

According to Wheatley (1999) transformation is strongly influenced by "strange attractors, 
which are self-portraits drawn by a chaotic system" (p. 123). Reigeluth (2004) mentioned that "fractals are patterns that recur at all levels of a system, called self-similarity" and added some examples:

...the autocratic control of education which appears in universities across the globe, the uniformity with which courses are formed in colleges and universities. Topdown control and uniformity are but two of many fractals that characterize our factory model of schools. (p. 8)

Strange attractors started to emerge in the new educational reality as well. Reigeluth (2004) mentioned that "one example of a strange attractor in education is empowerment/ownership, which entails providing both the freedom to make decisions and support for making and acting on those decisions" (p. 8). He added that "these core ideas stand in stark contrast to those that characterize the industrial-age mindset about the 'real school': centralization and bureaucracy, standardization (or uniformity), and autocratic management." We saw learners empower themselves and take ownership during the MobiMOOC not only by applying principles of self-organization but also because they were able to build their own mLearning project, giving rise to emerging knowledge and personalized learning. MobiMOOC participants indicated that they did indeed make use of what they learned in the course, pointing to the fact that knowledge acquired was directly applicable and beneficial to the advancement of their education in the mLearning field (see Figure 2).

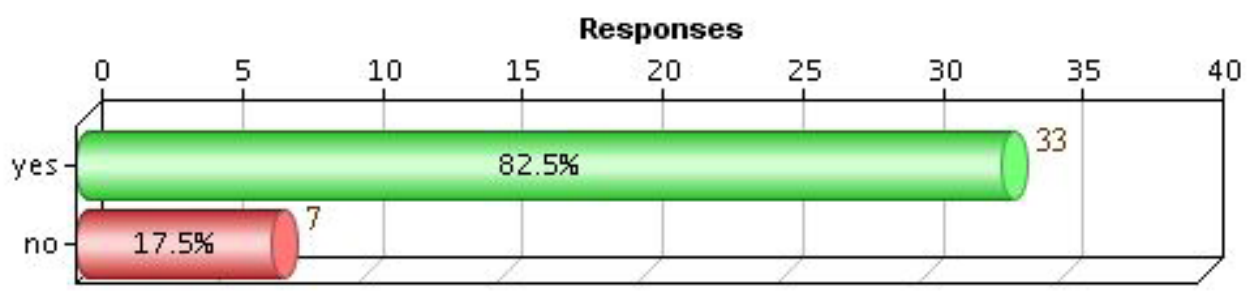

Figure 2. Have you been able to apply concepts or ideas that you encountered during the MobiMOOC in your own professional or personal context? $(N=40)$.

MobiMOOC also offered the participants the opportunity to develop their own educational project. In the final survey, many participants indicated that they worked on a personal project as well (Figure 3).

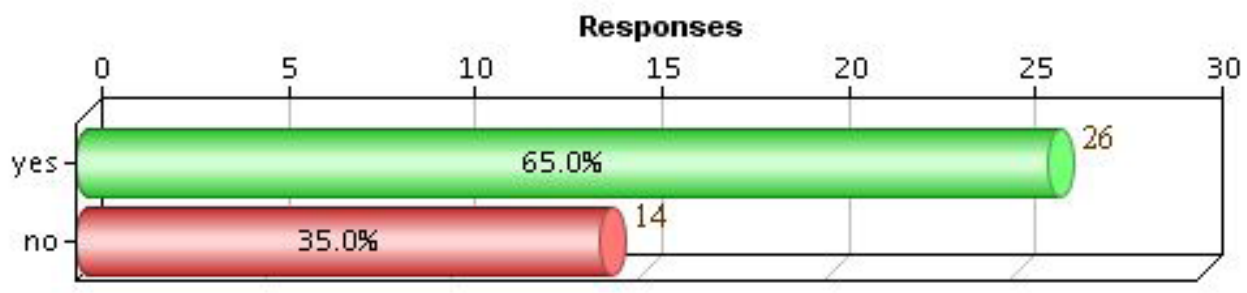

Figure 3. Did you work on a personal research-based mLearning project during the MobiMOOC? $(N=40)$. 
A second example Reigeluth (2004) mentioned is customization/diversification. This is ubiquitous on the Web, with people diversifying their reading and writing and their use of social media. Although that use seems to be very diverse, there are similarities in the use of social media for affordances are starting to become clear, such as perpetual connectivity, asynchronous interaction, unforeseen collaboration, and emerging learning opportunities. These social media affordances are already being embedded in MOOCs; for example, course syllabi are often offered to MOOC participants in the form of a course wiki, which was the case with the MobiMOOC as well.

In this section, we established the MobiMOOC as an example of an open and adaptive, complex system. This is important in the Knowledge Age because a wide variety of factors influence the learning/teaching process. If education is redesigned in order to suit the Knowledge Age, these self-organizing and open characteristics will be crucial.

Due to the openness of MOOCs and their ability to transform depending on the needs of the course or curriculum environment, we see new phenomena emerge which we will describe in the next section of this paper.

\section{Emerging Phenomena in MOOCs}

\section{Emerging Actions}

Minsk (1986) stated that very few of our actions and decisions depend on any single mechanism. Instead, they emerge from conflicts and negotiations among societies or processes that constantly challenge one another. "Interactions of many sub-components or agents, whose actions are in turn enabled and constrained by similarly dynamic contexts, result in emergent phenomena" (Davis \& Sumara, 2008, p. 34). Davis and Sumara (2008) have investigated the conditions that must be in place to allow these possibilities to emerge. They mentioned four important conditions linked to the MobiMOOC:

- internal diversity,

- internal redundancy,

- neighbor interactions,

- decentralized control.

\section{Internal Diversity}

Although diversity is an important factor, its impact cannot be foreseen. As Davis and Sumara (2008) wrote, "One cannot specify in advance what sorts of variation will be necessary for appropriately intelligent action, hence the need to ensure and maintain diversity in the current system" (p. 39). Davis and Sumara saw this diversity as an enhancer for fruitful discussions and successful knowledge creation, stating that an "intelligent response to the same circumstances might arise among the interactions of a network" (2008, p. 39). In 
the case of our research, the diversity of the MobiMOOC resulted in new insights that we shared.

MobiMOOC participants also showed diversity in both age (Figure 4) and gender (Figure 5), possibly indicating that the format attracts people from groups that typically don't interact.

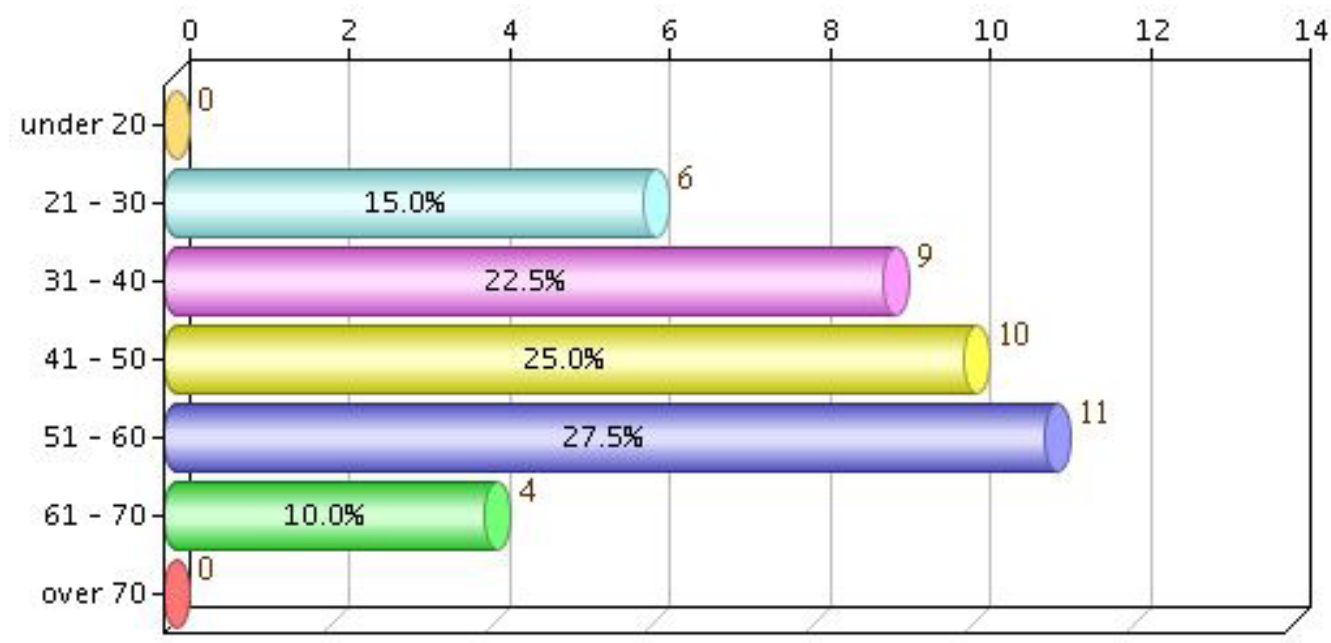

Figure 4. What is your age group? $(N=40)$.

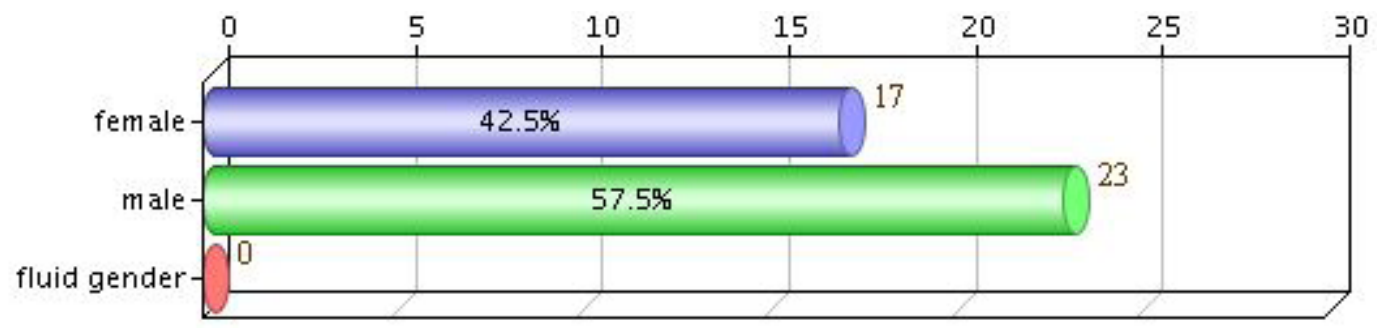

Figure 5. What is your gender?" $(N=40)$.

We saw diversity in the dispersion of the MobiMOOC participants across the globe as well. Figure 6 illustrates visits to the MobiMOOC crowdmap: For the MobiMOOC crowdmap there were 1,424 page views, 468 visits, and 372 unique visitors from 29 countries.

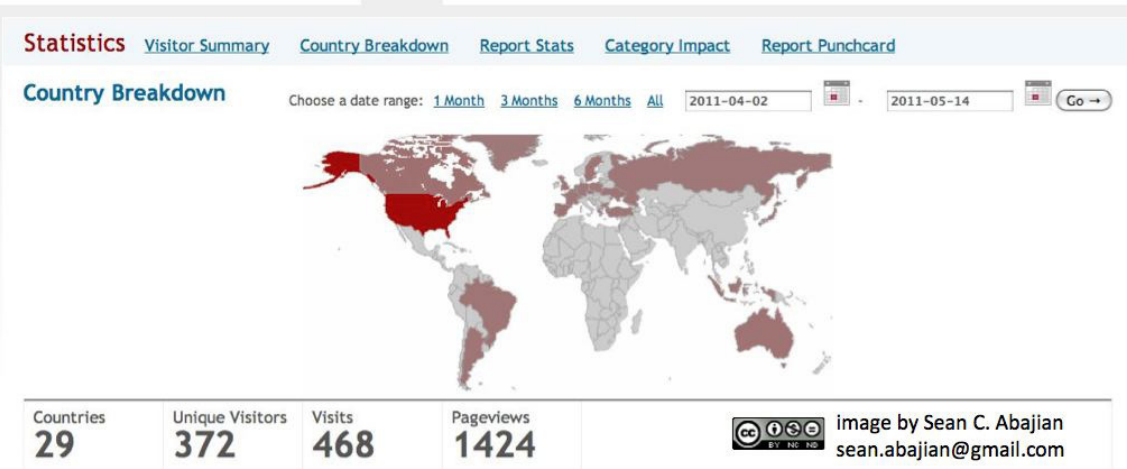

Figure 6. Overview of people accessing the social media tool MobiMOOC from countries 
around the world.

In the final survey it became clear that although MobiMOOC participants had a wide diversity of backgrounds (health professionals, $\mathrm{K}-12$ teachers, corporate training managers, language teachers, et cetera) most learned from mLearning concepts and insights from participants in other fields of expertise (see Figure 7).

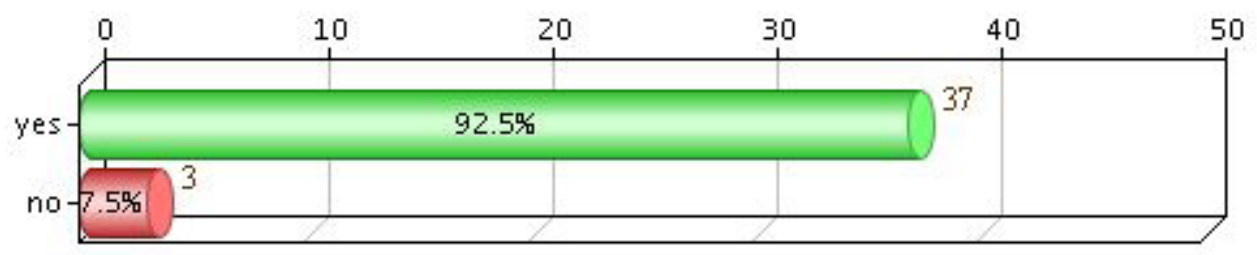

Figure 7. Did you discover new interests or new ideas from people in other areas of expertise than yours? $(N=40)$.

\section{Internal Redundancy}

The complement of internal diversity is internal redundancy, which refers to "duplications and excesses of those aspects that are necessary for complex co-activity" (Davis \& Sumara, 2008). In the MobiMOOC internal redundancy included, among other factors, a common language (although not everyone was a native English speaker, English was understood and used by all), a common interest in one specific educational technology (mLearning), the willingness to share ideas, and a certain digital literacy that enabled participants to follow the online course. This redundancy permits complex coactivity by fostering diversity.

Davis and Sumara (2008) stated that "among humans, there is vastly more redundancy than diversity," adding that "redundancy enables interactions among agents" (p. 39). Agents must be able to affect one another's activities in order to activate the internal dynamics of a collective learning system, hence our look at neighbor interactions.

\section{Neighbor Interactions}

When Davis and Sumara (2008) mentioned neighbor interactions, they specified that "the neighbors that must interact with one another are ideas, hunches, queries, and other manners of representation" (p. 40), in the hope that these interactions will trigger other insights. They also said "the critical point is that mechanisms be in place to ensure that ideas will stumble across one another" (p. 41). MOOCs support free interaction among participants, establishing a critical point of idea interaction and a place for the creation of knowledge.

Even though knowledge can be seen as residing in both humans and non-human appliances, it is what we do with that knowledge, and how we construct new knowledge, that is important. This is where a Vygotskian perspective is quite useful. According to Vygotsky (in Nassaji \& Swain, 2000), knowledge is social in nature and constructed through a process of collaboration, interaction, and communication among learners in social settings. We saw this happen in the MobiMOOC repeatedly. Through a process of collective scaffolding (Donato, 1994) some participants assisted others to expand their understanding of mLearning 
and in some cases also helped them implement their own mLearning projects. In many cases, participants received constructive feedback from their classmates on projects that they were either implementing or designing. This collective scaffolding enabled participants to work within the zone of proximal development (ZPD) (Vygotsky, 1978) and to expand their capabilities with the help of more knowledgeable peers. MobiMOOC ascribed to the Vygotsky principles of collaboration, interaction, and communication, revealed most clearly in the assistance participants offered to one another throughout the course.

\section{Decentralized Control}

Although there was a centralized coordinator and each MobiMOOC week was facilitated by a different mLearning expert, the participants had control over part of the advancement of the course. The MobiMOOC participants could, for instance, put forward discussion topics that were then taken up by others.

"One of the properties of complex systems is that they allow emergence of smaller complex systems within them" (Laroche et al., 2009). This happened as a result of decentralized authority and the fact that the participants were in control of their own learning. The dynamics of the MobiMOOC resulted in smaller complex subsystems that arose. This paper, for example, is a result of MobiMOOC participants who volunteered to join and engage in an emerging, unplanned action. Such an act is related to what Jenkins et al. (as cited in Davis \& Sumara, 2008) described as educational research based on complexity, for it

must be interpreted as participatory-meaning that there are opportunities for expression and engagement, there is support for creating and sharing creations, there is some type of teaching so the most experienced can mentor new members, members believe their contributions matter, and members feel social connection with one another. (p. 43)

Other emerging connections also occurred and resulted in participants setting up new collaborative projects, shown in Figure 8.

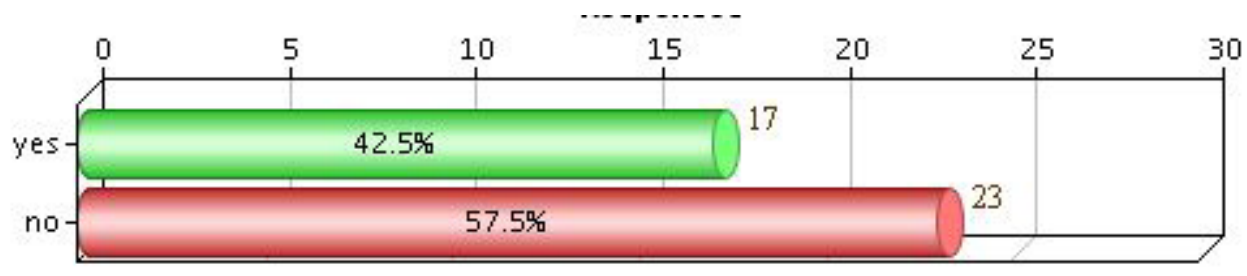

Figure 8. Have you connected to any other MobiMOOC participants in order to collaborate on projects after the MobiMOOC? $(N=40)$.

\section{Emerging Technologies}

“Transformation occurs through a process called 'emergence,' by which new processes and 
structures emerge to replace old ones in a system" (Reigeluth, 2004). When looking at the read-write Web, we can see that knowledge creation happens in different ways now than it did during the Industrial Age. The possibility for individuals to create knowledge and share it online replaces the old classroom exchange where the teacher knows and transmits, and the learner in turn absorbs. Looking at phenomena emerging from technologies can point us in the direction of a renewed educational equilibrium. The MobiMOOC offers the chance to look at two emerging technologies, mobile technology and social media technology, that have a major impact on the learning/teaching process.

\section{mLearning in MobiMOOC}

"mLearning has attracted a great deal of attention from researchers in different disciplines who have realized the potential to apply mobile technologies to enhance learning" (Özdamar \& Metcalf, 2011, p. 1). This focus on mobile technology-driven learning is only just emerging. "Early definitions of mobile learning were too technocentric and imprecise ... they merely put mobile learning somewhere on e-learning's spectrum of portability," remarked Traxler (2009, p. 3), which sells mLearning short. Laurillard (2007) made a strong point when she mentioned that "the point of turning to new technologies is to find the pedagogies that promote higher quality learning of a more durable kind than traditional methods" (p. 158). This "more durable" brand of learning is what we explored with the combination of the MOOC format and the pedagogy of mLearning.

Participants used mobile devices during the MobiMOOC. Although they did not always have to access materials via mobile devices, many did use them to interact with course materials (Figure 9). In the final survey of the MobiMOOC, participants indicated the reasons they preferred to use mobile devices to access course materials (Figure 10). The predominant reason participants gave for using a mobile device was the location independence it afforded. Participants were not tied to a desk in order to take part in class, rather they could contribute wherever they were. Closely tied to the location independence was the temporal independence. Participants were able to access materials at both a time and place convenient for them. Another reason why participants used mobile technologies to access the course was simply because they were there, and people exercised their ability.

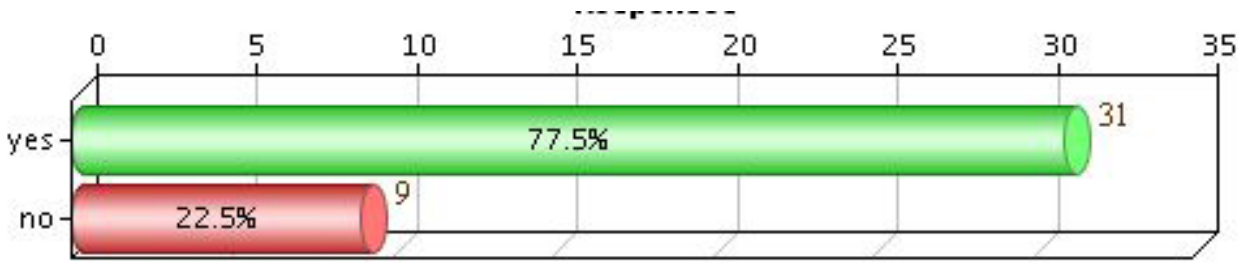

Figure 9. Did you use a mobile device to access MobiMOOC course materials? $(N=40)$. 


\begin{tabular}{lccl} 
Result & Responses & Percentage Graph \\
\hline time flexibility (no matter when) & 25 & $56.8 \%$ \\
location flexibility (no matter where) & 27 & $61.3 \%$ \\
the information was accessible through a mobile device & 13 & $29.5 \%$ \\
other & 6 & $13.6 \%$
\end{tabular}

Figure 10. If so, what was the reason to access the material with a mobile device (please check all that apply)? $(N=40)$.

mLearning first emerged as a strong technology-driven field but quickly garnered the interest of educational researchers for mobile devices and their use had an impact on knowledge creation. The fact that mLearning allows learners to access information and share knowledge no matter what time or place makes it a useful new addition to the learning/teaching process. Additionally, mLearning enables the learner to embed their own context, thus personalizing the learning path. Interestingly, some of these mLearning characteristics can be found in social media technology as well.

\section{Social Media Tools}

Social media has opened up spaces for learning. Learning discussions used to be confined to traditional classrooms or study groups within the physical university campus. Even in online courses, discussions were segregated behind the walls of the virtual classroom, but this is now changing rapidly. This shift in learning spaces puts pressure on the older, more limited learning spaces from the Industrial Age.

The use of social media is central to a MOOC as it allows the critical aspects of connectivity, communication, and interaction. Connectivity is important due to connectivism (from the theory perspective) and because MOOCs are online (the practical aspect). Communication and interaction are a part of connectivism and constructivism since learners can't cocreate knowledge if they can't communicate and interact. As such, we designed the MobiMOOC to include a variety of web-based tools. The coordinator chose to centralize the course around two web-based spaces: a MobiMOOC Google group and Wikispace. Both also had an RSS feed to keep participants informed about the latest inputs. The coordinator set up the Google group to centralize discussions, while the course wiki functioned as an online syllabus. Participants used other social media spaces, such as YouTube, Twitter, Facebook, and Delicious throughout the course for sharing specific content. In addition to the official MobiMOOC web spaces, some of the participants added other spaces during the MobiMOOC as well. Examples of these are the MobiMOOC Crowdmap, a MobiMOOC LinkedIn group, MobiMOOC Posterous blogs, the Zotero MobiMOOC group, and a MobiMOOC map based on Google maps. All of these web applications underline the complexity inherent in a MOOC that gives rise to emerging subsystems. 


\section{Bringing mLearning and Social Media Together}

Due to the pervasiveness of mobile devices in society, connecting to a community across space and time is becoming more relevant.

Mobile phones have created "simultaneity of place," a physical space and a virtual space of conversational interaction, and an extension of physical space, through the creation and juxtaposition of a mobile "social space." This affects people's sense of time, space, place, and location, their affiliations and loyalties to groups and communities, the ways in which they relate to other individuals and to groups, their sense of their identity, and their ethics. (Traxler, 2010, p. 2)

But the same can be said of social media, or the rise of ubiquitous learning. Due to the use of social media, people, and learners in particular, can surpass time and space. As Siemens (2005) wrote, learning is now happening "through communities of practice, personal networks, and through completion of work-related tasks" in an environment in which "knowhow and know-what is being supplemented with know-where (the understanding of where to find knowledge needed)" (p. 4).

This is the first time in history that learning content can be accessed via mobile devices and social media. These tools expand knowledge acquisition beyond traditional classrooms and libraries, redefining those spaces and adding to knowledge spaces overall. When describing mLearning, Winters (2007) listed three interesting aspects: mLearing enables knowledgebuilding by learners in different contexts, it enables learners to construct understandings, and the context is about more than time and space. Indeed, the same can be said about learning through a MOOC. A MOOC surpasses time and space as all the class resources are centralized in the cloud, accessible for those who are willing and technologically able (that is, those who have the right devices, sufficient training, and physical/mental ability). Similar to mLearning, a MOOC fits the learners' context(s) and enables knowledge construction. Like Bell (2011) said, "knowledge can be viewed as residing in networks of humans and non-human appliances, whilst leaving space for human agency.”

In this part of the paper, we have shown that a MobiMOOC includes both new learning actions and the integration of emerging technologies. This openness to stimulating emerging phenomena and incorporating them into its structure is essential in a Knowledge Age where technological development and peer knowledge creation is at the center of the new educational environment.

\section{Dialogues at the Center of Meaning}

The successful development of online communities also requires "common goals or interests, repeated participation, discussions and feedback, multiplicity of possibilities, flexible 
thinking structures, interpersonal connectivity, collaboration, interactions, distributed leadership, assigned roles, and shared outcomes" (Abel, 2005; Farrior, 2005; Kelland, 2006; Kim, 2001 as cited in Laroche et al., 2009). If we analyze these requirements-discussions, feedback, collaborations, et cetera-it becomes clear that conversations between people are at the center of those online communities. This exchange of ideas that goes back and forth between members of a community is essential, because "more than any other way, people learn not from courses or Web sites but from each other ... through dialogue" (Rosenberg, 2006, p. 158). Dialogue has always been integral to human communication and growth.

"The rapid development of technology and exponential growth in the use of the Internet, along with the Web 2.0 and mobile developments, make new and different educational structures, organizations, and settings a possibility" (Kop \& Hill, 2008, p. 9). But due to all these societal changes, the dynamics between people are growing more complex as well. As the Knowledge Age becomes more of a reality, that complexity reaches the field of learning and education and trickles down to MOOCs. Communication, dialogue, and living through experiences in a collaborative way are central to the idea of a MOOC. Since one of the central content spaces in the MobiMOOC was a Google group which promoted discussions, the coordinators incorporated dialogue in the core of the course.

Traxler's belief that "mobile technologies are redefining models of learning that often rest on a Socratic or dialogic base" (Traxler, 2010, p. 13) adds to Sharples' (2005) idea that learning is a conversation in context. This emphasis on dialogue and conversations is also mentioned by Siemens (2008), who wrote that learning and knowledge "rest in diversity of opinions" (para. 8, as cited in Kop \& Hill). Diversity, as previously established, is a core component of the MobiMOOC experience.

Cultural theorists (Vygotsky, 1962; Derrida, 1976; Bakhtin, 1981) have suggested that all of our understandings are situated in and emerge with complex webs of experience, so we can never discern the direct causes of any particular action. Learning is also strongly contextualized. Davis and Sumara mentioned (1997) "as the learner learns, the context changes, simply because one of its components changes." As such, they conclude that "any teaching/ learning situations are intricately, ecologically, and complexly related” (p. 414).

As a $\mathrm{MOOC}$ is a gathering of people with almost no prior connection, it has a unique social edge which relates to a more open and connected way of thinking and conversing. This coincides with what Downes (2007) wrote, that the "activities we undertake when we conduct practices in order to learn are more like growing or developing ourselves and our society in certain (connected) ways.

Dialogue is also at the center of constructing knowledge since "dialogue is the primary mechanism for maintaining connections and developing knowledge through them" (Ravenscroft, 2011). While a MOOC is an ideal place for dialogue to take place and, as such, for knowledge to be constructed or appear, the same is true for mLearning, as 
with mobile devices the learning environment is enhanced and the ability to share knowledge through online discussion is strengthened through social media. The sharing of experiences in a network facilitates the transformation of learning outcomes into permanent and valuable knowledge assets. (de Waard \& Kiyan, 2010, p.

5)

Learning is not a linear process; it is a continued iteration which links to prior knowledge. That knowledge can then be modified after evaluating the new information and integrating it. As such, learning and knowledge are in a constant state of flux. This fluctuating state of knowledge is even more emphasized in informal learning for the learner is taking his or her own interpretation and testing it against the ideas of other participants. In the MobiMOOC, this sharing of new ideas was clearly not limited to the course participants. Participants took the new information and ideas out of the course and tested it in other learning networks as well. This multiplication effect is shown in Figure 11.

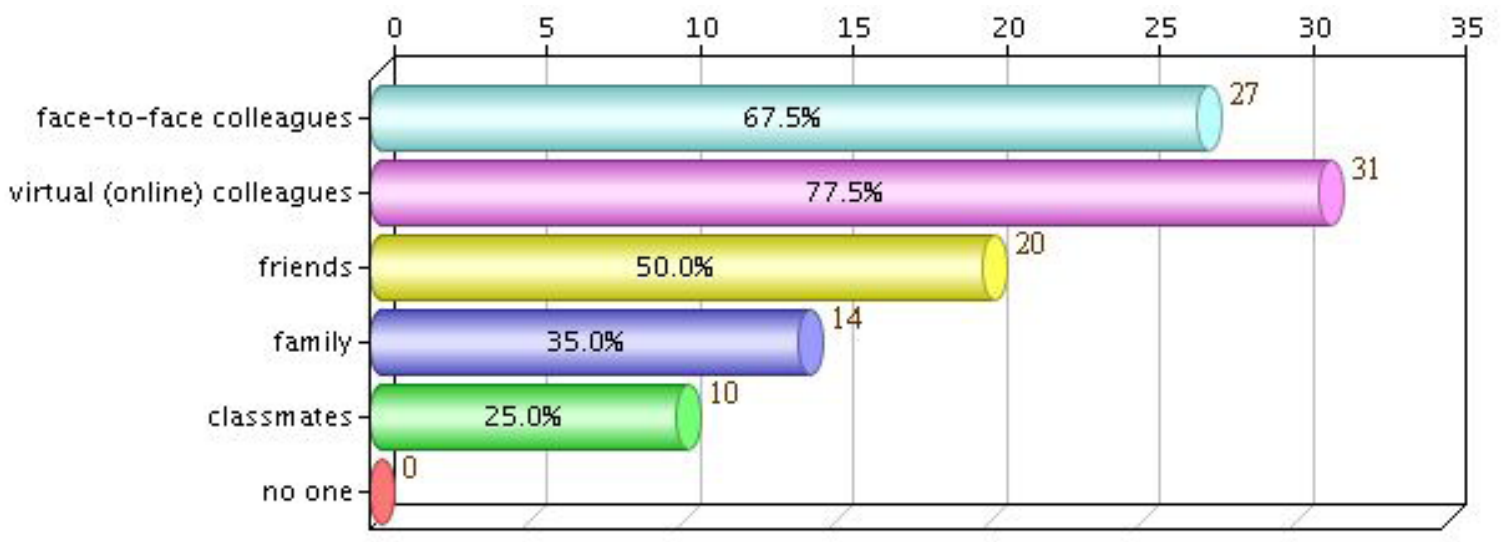

Figure 11. With whom outside of the MobiMOOC did you share what you have learned in the MobiMOOC? $(N=40)$.

And when we asked participants how they shared information, again they listed a mix of face-to-face, mobile phone, and social media dialogues (see Figure 12), once more pointing to dialogue as a core feature of learning in any world, whether face-to-face or digital. 


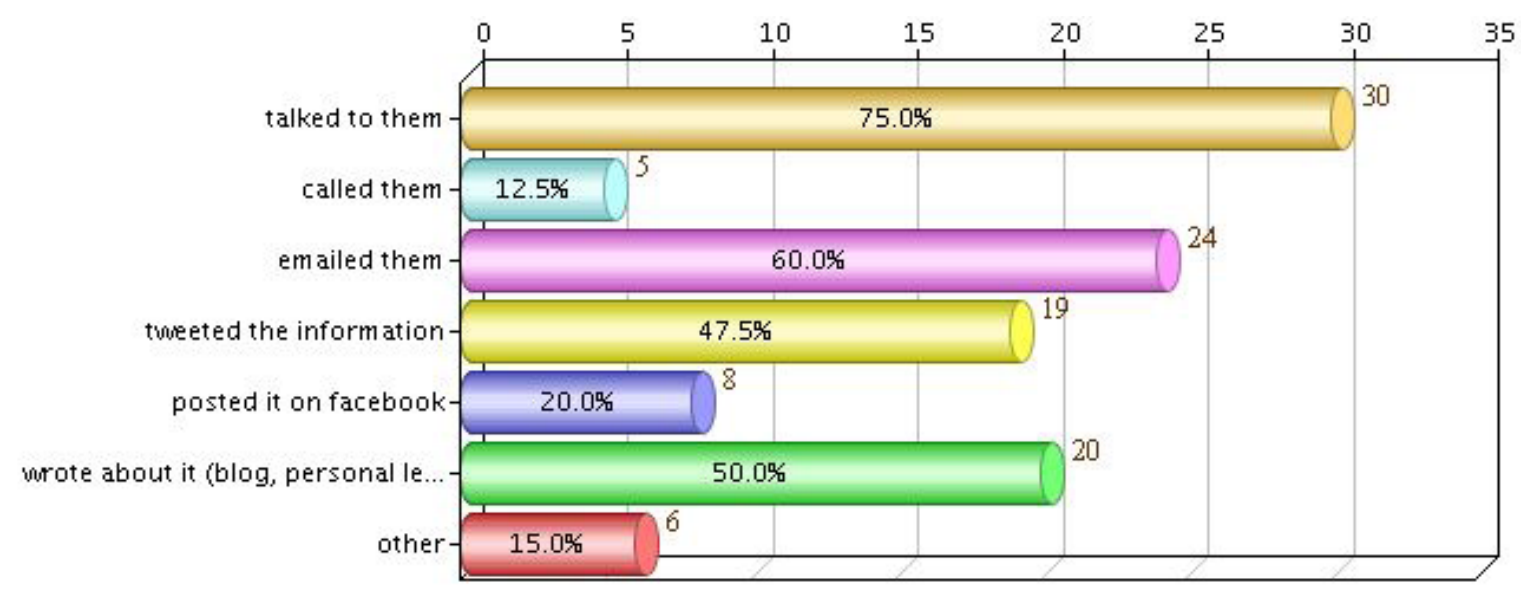

Figure 12. If you shared information with others, how did you share it? $(N=40)$.

Our understanding that dialogue is a human aspect of both communication and learning results from the belief that the MOOC format could also benefit other learning communities due to its very open nature of constructing new knowledge and its very human characteristic of connecting to peers. This belief was strengthened by the result from the final survey shown in Figure 13.

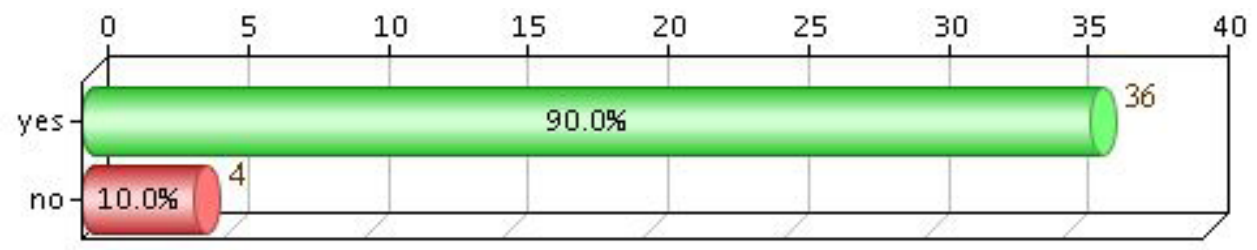

Figure 13. Do you think the MOOC format is appropriate for your learning communities? $(N=40)$.

Based on our findings in this study, we can see that dialogue has always been at the center of knowledge exchange. However, it has never before been possible to include large parts of society in the conversation. Patterns of meaning can be formed across regions and institutions if a network of connected people comes together. If educators want to form a new educational framework, it needs to be stimulated by dialogue emerging in virtual, online spaces. The MOOC format enhances dialogue, and, as such, it strengthens educational combinations of contemporary technology and pedagogy.

\section{Further Research}

Chaos theory in education is still in its infancy when we take into account the new technologies and formats that are rising in this Knowledge Age. Devices and programs continue to change, so there is considerable uncertainty about what will be the best new educational framework for the Knowledge Age, and attempts to address this question form an interesting research strand. 
mLearning and MOOCs consist of a variety of factors, and each might influence the success of a MOOC as a new educational format. More research should be undertaken into the realities, benefits, and challenges of MOOCs and mLearning in order to map all of their contributing dynamics.

Further research is needed to determine whether MOOCs are attracting a specific learner profile not linked to age, gender, or cultural background, but rather to intrinsic and extrinsic motivations.

We found the retention rate of the MobiMOOC interesting as after the course closed, the network between the participants remained active, indicating that they feel the MobiMOOC community is more useful than we previously anticipated.

There is also a need to determine design principles for MOOCs to effectively maximize their self-organizing, self-referencing, and knowledge-producing capabilities. We believe it would also be helpful to see the ethnic and socioeconomic breakdown of participants in a MOOC to determine whether this format is actively promoting participation from any particular demographic. Finally, the affordances of mLearning and social media need to be investigated in order to use them in the new educational environment.

\section{Conclusion}

Reigeluth (2004) already pointed educational researchers in the right direction when he wrote that chaos theory and the science of complexity can help us to understand and improve the process in which educational systems engage to transform themselves. When looking at the shift in learning which is happening as a result of the rise in social media, ubiquitous cloud computing, and new technologies, a MOOC complements all these changes, and mLearning offers the devices and characteristics to realize them.

The MobiMOOC we ran was an example of an open and adaptive, complex system. The technologies that we used gave rise to emerging phenomena in its activities. Additionally, dialogues were central to knowledge creation within the MobiMOOC. This combination of factors that characterize MOOCs which use new technologies make them a possible solution in the search for new educational environments that fit this Knowledge Age. Education is changing under the influence of a wide variety of factors, and there is a need to further investigate all of them so that the research community can come up with a redesigned framework in which emerging technologies enrich educational institutes, tools, and formats.

In this paper we have embedded MobiMOOC and MOOCs in a framework of chaos theory, complexity, and emergence. 


\section{References}

Abel. R. (2005). Implementing best practices in online learning. Educause quarterly: The IT Practitioner's Journal, 28(3), 75-77.

Bakhtin, M. M. (1981). The dialogic imagination. Austin: University of Texas Press.

Bell, F. (2011). Connectivism: Its place in theory-informed research and innovation in technology-enabled learning. International Review of Research in Open and Distance Learning, 12(3). Retrieved from http://www.irrodl.org/index.php/irrodl/article/ view/902/1664

Bertuglia, C. S. (2005). Nonlinearity, chaos and complexity: The dynamics of natural and social systems. Oxford: Oxford University Press.

Cafolla, R. (2008). Industrial age paradigm vs. information age (chaos) paradigm. Retrieved from http://www.coe.fau.edu/faculty/cafolla/courses/eme6051/chaos/ Applications.htm

Davis, B., \& Sumara, D. (1997). Cognition, complexity, and teacher education. Harvard Educational Review, 67(1), 105-125.

Davis, B., \& Sumara, D. (2008). Complexity as a theory of education. Transnational Curriculum Inquiry 5(2), 33-44. Retrieved from http://nitinat.library.ubc.ca/ojs/ index.php/tci

Davis, B., \& Sumara, D. (2010). “If things were simple...”: complexity in education. Journal of Evaluation in Clinical Practice, 16(4), 856-860.

Derrida, J. (1992). Acts of literature. New York: Routledge.

de Waard, I., \& Kiyan, C. (2010, October). Mobile learning for HIV health care workers' training in resource-limited settings. Paper presented at mLearn 2010, Malta.

Donato, R. (1994) Collective scaffolding. In J. P. Lantolf \& G. Appel (Eds.), Vygotskyan approaches to second language research (pp. 33-56). Norwood, NJ: Ablex.

Downes, S. (2007). What connectivism is. Paper presented at the Connectivism Conference, University of Manitoba, Winnipeg. Retrieved from http://halfanhour.blogspot. com/2007/02/what-connectivism-is.html

Farrior, M. (2005). Best practices for building online communities between researchers and practitioners. Retrieved from https://www.ohrd.wisc.edu/home/portals/o/ Bestpracticesforbuildingonlinecommunities. doc

Iannone, R. (1995). Chaos theory and its implications for curriculum and teaching. Education, 115(4), 541-547. 
Kelland, J. H. (2006). Constructivist theories and online learning best practices: A discourse analysis. Canadian Association for the Study of Adult Education (CASAE) 2006 National Conference On-Line Proceedings, York University, Toronto, Ontario.

Kop, R., \& Hill, A. (2008). Connectivism: Learning theory of the future or vestige of the past? International Review of Research in Open and Distance Learning, 9(3). Retrieved from http://www.irrodl.org/index.php/irrodl/article/view/523/1103

Kukulska-Hulme, A., \& Traxler, J. (2007). Designing for mobile and wireless learning. In H. Beetham \& R. Sharpe (Eds.), Rethinking pedagogy for a digital age (pp. 183192). New York: Routledge.

Laroche, L., Nicol, C., \& Mayer-Smith, J. (2007). New venues for science teacher education: Self-organizational pedagogy on the edge of chaos. Complicity: An International Journal of Complexity and Education, 4(1), 69-83.

Laurillard, D. (2007). Pedagogical forms for mobile learning. In N. Pachler (Ed.), Mobile learning: Towards a research agenda (pp. 153-175). London: WLE Centre, IoE.

Mackness, J., Mak, S., \& Williams, R. (2010). The ideals and reality of participating in a MOOC. Paper presented at the Seventh International Conference on Networked Learning, Aalborg, Denmark. Retrieved from http://www.lancs.ac.uk/fss/organisations/netlc/past/nlc2010/abstracts/PDFs/Mackness.pdf

McAuley, A., Stewart, B., Siemens, G., \& Cormier, D. (2010). The MOOC model for digital practice. Retrieved from http://www.elearnspace.org/Articles/MOOC Final.pdf

McNeely, I., \& Wolverton, L. (2008). Reinventing knowledge, from Alexandria to the Internet. New York: Norton \& Company.

Minsk, M. (1986). The society of the mind. New York: Simon \& Schuster.

Moore, M., \& Kearsley, G. (2005). Distance education: A systems view. Belworth, CA: Thompson Wadsworth.

Nassaji, H., \& Swain, M. (2000). A Vygotskian perspective on corrective feedback: The effect of random versus negotiated help on the learning of English articles. Language Awareness, 9, 34-51.

Özdamar Keskin, N., \& Metcalf, D. (2011). The current perspectives, theories and practices of mobile learning. The Turkish Online Journal of Educational Technology, 10(2), 202-208.

Ravenscroft, A. (2011). Dialogue and connectivism: A new approach to understanding and promoting dialogue-rich networked learning. International Review of Research in 
Open and Distance Learning, 12(3). Retrieved from http://www.irrodl.org/index. php/irrodl/article/view/934

Reigeluth, C. M. (2004). Chaos theory and the sciences of complexity: Foundations for transforming education. Paper presented at the annual meeting of the American Educational Research Association, San Diego, CA.

Rosenberg, M. J. (2006). Beyond e-learning. San Francisco: Pfeiffer.

Sharples, M. (2005). Learning as conversation: Transforming education in the mobile age. Proceedings of Conference on Seeing, Understanding, and Learning in the Mobile Age, Budapest, Hungary (pp. 147-152). Retrieved from http://www.eee.bham. ac.uk/sharplem/Papers/Theory\%20of\%2olearning\%20Budapest.pdf

Siemens, G. (2005). Connectivism: A learning theory for the digital age. International Journal of Instructional Technology and Distance Learning, 2(1). Retrieved from http://www.itdl.org/journal/jan 05/articleo1.htm

Traxler, J. (2009). The evolution of mobile learning. In R. Guy (Ed.), The evolution of mobile teaching and learning (pp. 1-14). Santa Rosa, CA: Informing Science Press.

Traxler, J. (2010). The learner experience of mobiles, mobility and connectedness. Paper published by ELESIG (Evaluation of Learners' Experiences of e-Learning Special Interest Group). Retrieved from http://www.helenwhitehead.com/elesig/ELESIG\%20Mobilities\%20ReviewPDF.pdf

Vygotsky, L. S. (1978). Interaction between learning and development. In L. S. Vygotsky (Ed.), Mind in society (pp. 79-91). Cambridge, MA: Harvard University Press.

Wheatley, M. J. (1999). Leadership and the new science: Discovering order in a chaotic world. San Francisco: Berrett-Koehler Publishers.

Winters, N. (2007). What is mobile learning? In M. Sharples (Ed.), Big issues in mobile learning (pp. 7-11). Nottingham, UK: LSRI, University of Nottingham.

\section{Athabasca University $\mathbf{I}$}

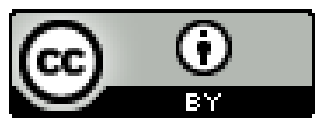

